\title{
Evaluation of Public Service Motivation: A Case Study of Hefei Public Sector Organizations
}

\author{
Sadiq \\ School of Public Affairs, University of Science and Technology of China \\ No.96 Jinzhai Road, Baohe District, Hefei, Anhui 230026, China \\ E-mail: Sadiq@mail.ustc.edu.cn
}

Received: December 2, 2017 Accepted: December 21, 2017

doi:10.5296/ber.v8i1.12530ＵRL: https://doi.org/10.5296/ber.v8i1.12530

\begin{abstract}
This paper highlights the effects of 'Public Service Motivation' (PSM) in public sector organizations. This research explores the relationship between employees' motivation (intrinsic expectation \& extrinsic expectation), goal clarity and employees' participation with 'Public Service Motivation' (PSM). A questionnaire was used in this research to conduct a survey. About $70 \%$ response rate was generated out of 300 employees located in different public sector organizations of Hefei city of Anhui province in P.R.China, including health, education and High-Tech firms. The Scope of this study is delimited to the public sector organizations of Hefei City China. The result shows that there is a strong positively significant relationship of employees' motivation, participation, and goal clarity with 'Public Service Motivation' (PSM), which can be further strengthened by innovative organizational culture.
\end{abstract}

Keywords: 'Public Service Motivation' (PSM), Employees Motivation, Extrinsic Motivation, Intrinsic Motivation, Organizational Culture, Employees Empowerment, Goal Clarity, Public Sector Institutions/Organizations.

\section{Introduction}

Every organization sets some rules and draws some boundaries to deliver result oriented performance. To achieve proposed targets organizations are setting some measurable and quantifiable performance indicators. The effective utilization of these measurable and quantifiable performance indicators may result in organizational success and achievement of organizational goals. To successfully identify different success factors for any organization is not an easy task. It takes more than efforts to identify and successfully implement these factors and indicators of organizational performance. The changing nature of the 
organizations and the level of competition they are facing making it difficult for organizations even to survive, this is true especially for public sector organizations, and it's really hard for public sector organizations to stay relevant and effective. Globalization is the driving force behind most of the challenges organizations are facing right now. Other challenges for public sector organizations are the changing nature of demands, awareness, demographic challenges, and economic trends. Approaches like public service motivation are adopted in Hefei public sector organizations to face these challenges, to achieve organizational goals, and to ensure effective and smooth operations. However, HRM \& PSM is still in its early stages in Hefei governmental sector organizations.

This research will be a substantial contributing to the literature and body knowledge of employee motivation, which includes intrinsic and extrinsic motivation and organizational culture, which includes employees goal clarity and employee empowerment with respect to public service motivation. This research is mainly focused on the relationship between public service motivation, employee motivation, and organizational culture. Last but not the least; this study is conducted in different public sector organizations having different and unique characteristics.

\section{Literature Review}

\subsection{Public Service Motivation (PSM)}

In this study the only independent variable is public service motivation. According to Perry \& Wise (1990), Vandenabeele \& Ban (2009) Verbeeten (2008) Public Service Motivation is a good measurement for predicting employee attitude and behavior in public sector organization as compare to some other behavioral measurements. The theory of Public service motivation was first introduced by Bushanan in 1975, and Rainey (1982) was the researcher on public service motivation to use the term public service motivation in his paper. The nature and idea of public Service motivation is evolving and going through constant development (Perry \& Wise, 1990). According to Perry \& Wise, (1990) definition of PSM " it's an individual jurisdiction to have a reaction to intentions grounded principally or exceptionally in public institutions and organization". The early suggestions to explore the field of PSM came from Perry \& Wise (1990), they were the first academician proposing extensive research in the field of PSM in public sector institutions. Rainey \& Steinbauer (1999) defined PSM as "a common philanthropic enthusiasm to work in the best interest of a public, community, a state, a nation or mankind”. Perry \& Hondeghem (2008) defined PSM as "the faith, ethics and attitude that is above selfishness or structural interest, that's concerns a large political body and that encourage through public relations, inspiration for directed action". The most recent definition of Public Service Motivation (PSM) by Wright, Hassan, \& Christensen (2017) in their research linked PSM to the upbringing of a person's formative years and personal characteristics that lies deep down in someone personality. According to Pandey, Wright, \& Moynihan (2008) Public Service Motivation (PSM) is a good facilitator of desirable organizational behavior. Rainey \& Steinbauer (1999) in their research on Public Service Motivation recommended to include PSM along with other characteristics for the effectiveness of public service intuitions. According to Brewer \& 
Selden (2000) Public Service Motivation (PSM) is a "prevalent phenomena in public sector organizations" which cannot be ignored.

\subsection{Employee Motivation}

Robbins (2009) defined Motivation as a tool helping individual's efforts, mobilizing it, directing, and supporting it towards specific goals. to know the right elements of employees motivational factors will enable us to make goal oriented evaluation about what the employees expect from their occupations and jobs and either they are feeling getting it or not (Blumberg \& Pringle, 1982; Scully, 1993). If an organization offer job security the employee will likely remain loyal and committed to the organizational goals. job security include pay, pension's benefits, no reduction in seniority and some other benefits and remunerations (Yousef, 1998). In past, researchers studied job security, pay to measure and assess the magnitude of extrinsic motivation on PSM.

\subsubsection{Employee Motivation and PSM}

The relationship between employee motivation and PSM have been studied in numerous studies around the world but mostly in developed countries(Bright, 2008; Naff \& Crum, 1999; Panagiotis, Alexandros, \& George, 2014) and the outcome of these studies confirming a direct relationship between employees motivation and PSM. These studies generalized claims about enhancing employee performance through motivation to get effective public service motivation (Bellè, Bocconi, \& Bocconi, 2010). The following hypothesis concludes the above literature review.

Hypothesis 1a: 'Intrinsic motivation factors' have strong positive association with the 'Public Service Motivation' (PSM)

Hypothesis 1b: 'Extrinsic motivation factors' have strong positive association with the 'Public Service Motivation' (PSM)

\subsection{Organizational Culture}

Organizational aspects such as organizational mission and organizational goals have been studied with respect to organizational culture and innovation(Drucker, 1985). According to Zeffane (1996) the basic leverage points which effect the organization morals and performance are five, organizational culture is one of those five basic leverage points. In addition to other aspects of organizational culture empowerment and goal clarity has been outlined as core elements for organizational productivity and organizational performance (Hart, 1998). There are many aspects of organizational culture but this study will only focus on two aspects which are goal clarity \& empowerment.

\subsubsection{Employee Empowerment}

In literature of employee empowerment most often the cited definition of employee empowerment is the one proposed by Conger \& Kanungo (1988). According to Conger \& Kanungo (1988) employee empowerment" is a process that nurtures the spirit of self-efficacy between organizational employees through identification of circumstances that nurture 
powerlessness, and by both formal organizational practices and informal techniques remove them by proving efficacy information". Conger \& Kanungo (1988) also proposed a definition of employee empowerment as it's the progression of delegation of legislative authority, delegation of power, and delegation mission and sector power. According to Ugboro \& Obeng (2001) employee empowerment is the process of empowering the organizational workforce to react to any organizational problem in the best possible way by granting them some authority to do so. According to Hart (1998) employees empowerment facilitates an increase in the creativity of an employee to deliver the service in the best possible and way.

\subsubsection{Goal Clarity}

We can define goal clarity in terms of as it's the clear and directive way in dealing with state of business affairs to achieve a proposed goal or plan and that (when attained) conclude conduct was planned to attain it. Similarly, we can say that the end results will justify the means (Rainey, 1982). According to some authors like Rainey \& Steinbauer, (1999) suggested that goal setting theory to set specific goals within organization will leads to higher performance. According to Hart (1998) organizational members will increaser their efforts and commitment to the organizational goals, because they accept and value organizational goals.

\subsubsection{Goal clarity, Empowerment and Public Service Management (PSM)}

The relationship among variables like goal clarity, employee empowerment and PSM is a chicken-and-egg dilemma. This particular study presumes that clarified individual and organizational goals along with organizational means \& resources, freedom \& autonomy and sense of efficacy will lead to achieve organizational goals and performances.

Buchanan, Claydon, \& Doyle (1999) presented the similar findings and stated that organizational member's attachment to organizational goals, values and objectives are not only good in nature \& themselves but a useful way for rewarding individuals who struggle to achieve those values, goals and objectives. The best way of depicting a phenomenon of accomplishing one's moral responsibilities as a member of organization is by using disciplined decisions through means of empowerment within organizations. The aforementioned literature review of organizational goals and empowerment leads us to the valuation of influence of employee empowerment and goal clarity on PSM.

The above discussion enabled us to draw the second hypothesis for this research.

Hypothesis 2: 'Goal clarity' and 'Empowerment' have strong positive association with the 'Public Service Motivation' (PSM).

\subsection{Employment Level and Public Service Motivation (PSM)}

It's a well-known fact that in most developing countries the productivity of private sector is much better than that of public sector institutions and organizations. In most emerging economies and developing nations to increase the productivity of public sector organizations the competent supervisors and workers who are capable to increase the productivity of public sector organizations are not that many in numbers, who have the insight and ability of 
sophisticated technical, financial and managerial complexity of public sector organizations (Grindle, 1997). According to Ghobadian, Gallear, Viney, \& Oregan (2007) employees of public sector organizations have lower level of public service motivation compare to private sector. Many other scholars also presented the same findings for example Balfour \& Wechsler (1990) presented and interesting insight that public sector may be enjoying a high degree of internationalizations, however, will not have a high level of PSM. This study is focuses on the identification of the nature of motivational factors required for goal clarity, and the significance of empowerment postulating that these factors significantly affect PSM.

Many researcher corresponded to the concern of decline in moral and motivation among employees of public sector organizations (Charbonneau \& Van Ryzin, 2017), many researcher and scholars began paying attention to aspects like satisfaction with Job, commitment with organization, and motivational problems in public sector institutions and organizations. All of these researchers came up with mix conclusions and findings, however some researcher (Balfour \& Wechsler, 1990) found the entire opposite or inadequate results. According to Naff \& Crum (1999) the motivational base for public sector is entirely different and unique. In a study by (Kingsley \& Reed, 1991) conducted a research on the effects of employment level in public sector organizations. Power-based theory suggests that there is significant and positive association between organizational commitment, PSM, and power-related variables (Wilson, 1999)(Panagiotis et al., 2014).

The above discussion and review of literature enabled us to draw the third hypothesis of this study.

Hypothesis 3: 'Employment level' have a strong positive association with 'Public Service Motivation' (PSM).

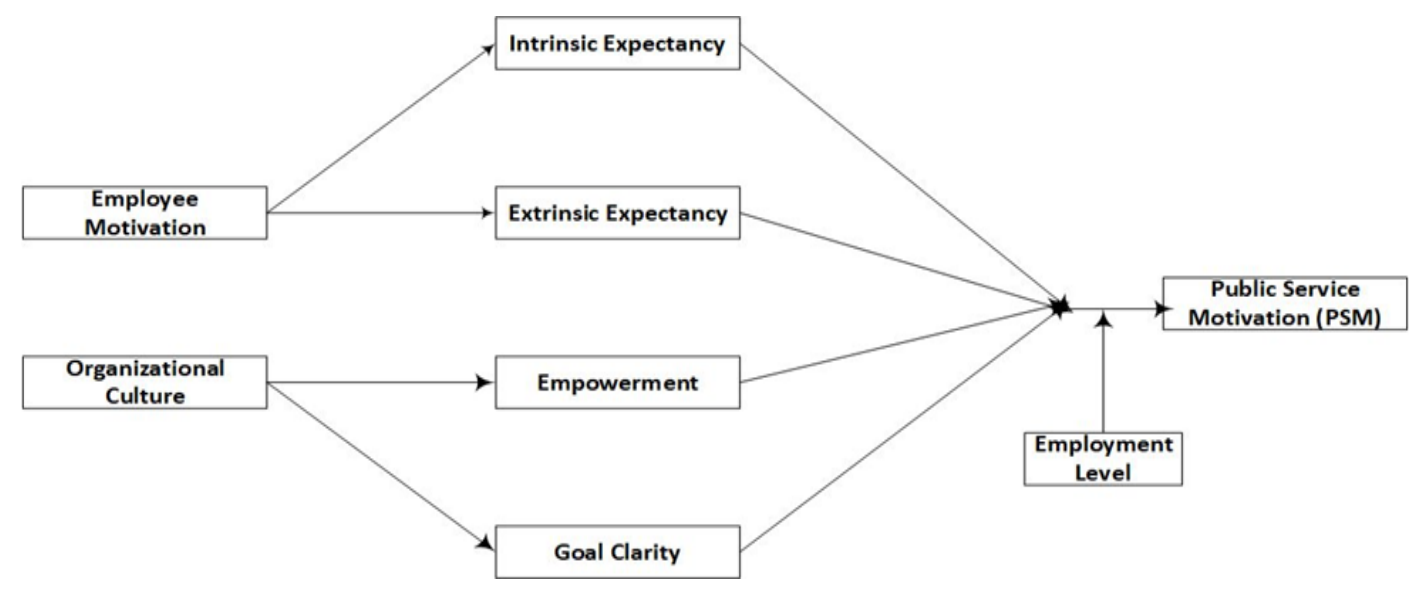

Figure 1. Theoretical framework for current study depicting relationship and association between variables

\section{Research Methodology}

To test the association and relationship between variables of this study which are employee motivation, organizational culture, and PSM this study adopted and followed the rational 
approach. The instrument used in this study was derived and validated from literature, but, still the reliability of this instrument was tested which turned out to be 0.81 which is considered a good reliability in statistics (Gliem \& Gliem, 2003). About 210 people responded to the survey instrument form 17 different organizations and industries. The employees selected for this survey were top, middle and lower level or front line employees having a direct interaction with customers. About $70 \%$ response rate was generated from out of 300 employees located in different public sector organizations of Hefei city, including health, education, police, Hi tech and energy.

A non-probability sampling was adopted for data collection. The instrument used in this study for data collection was a questionnaire. The questionnaire used in this research to generate responses is "structured close ended questionnaire" where ' 1 ' was assigned for strongly agreeing and ' 5 ' was assigned for strongly disagreeing. Organizations were visited personally for collecting the data. Total numbers of questionnaires distributed were 300. Only 210 questionnaires were returned as accurately filled questionnaires (70\% response rate). Employment level (top and middle level is the only moderating variable used in this study. In order to identify the relationship between variables and the magnitude of independent variables on dependent variable regression and correlation analysis were used.

\section{Findings, Discussion}

This research has been conducted to analyze the impact factor of organizational culture and employees' motivation on PSM in different public sector organizations of Hefei city across different administrative level.

The following demographic trends in Table $\mathbf{1}$ are detected in descriptive analysis in the sample for this study.

Table 1. Respondents demographic analysis

\begin{tabular}{|l|l|l|l|}
\hline Category & Classification & Frequency & Percentage \\
\hline Gender & Male & 157 & $74.8 \%$ \\
& Female & 53 & $25.2 \%$ \\
\hline Respondents & High level & 73 & $34.8 \%$ \\
level & Middle Level & 108 & $51.4 \%$ \\
& Low Level & 29 & $13.8 \%$ \\
& High School & 5 & \\
Educational & Bachelors & 109 & $2.4 \%$ \\
Level & Masters & 67 & $51.9 \%$ \\
& Above & 29 & $13.9 \%$ \\
& & & \\
Experience & Less than 1 year & 16 & $7.6 \%$ \\
Level & $1-5$ years & 13 & $6.2 \%$ \\
& 5-10 years & 85 & $40.5 \%$ \\
& 15 and above & 12 & $40.0 \%$ \\
& & & $5.7 \%$ \\
& & & \\
\hline
\end{tabular}

The proportion of male participants for this study was 157 (74.8\%) out of the total proportion of 210 participants, while the proportion of female participants was 53(25.2\%) out of the total proportion of 210 participants. Among the participants of this study 73 (34.8\%) were high level employees, 108(51.4\%) were middle level employees, and 29(13.8\%) were lower 
level employees. Among 210 participants 5(2.4\%) have high school education, 109(51.9\%) have bachelor degrees, 67(31.95\%) have master's degrees, and 29(13.8\%) have educational level above master's. The descriptive analysis shows that $16(7.6 \%)$ participants of this study have less than 1-year experience, $13(6.2 \%)$ posses $1-5$ years of experience, $85(40.5 \%)$ have 5-10 years of experience, $84(40.0 \%)$ have experience of 10-15 years, while those who have the experience of more than 15 years are counted $12(5.7 \%)$ of the total sample size.

Table 2. Cronbach's Alpha

\begin{tabular}{|l|l|l|}
\hline Variables & $\begin{array}{l}\text { No } \\
\text { of } \\
\text { Items }\end{array}$ & $\begin{array}{l}\text { Cronbach's } \\
\text { Alpha }\end{array}$ \\
\hline $\begin{array}{l}\text { Intrinsic } \\
\text { Expectancy }\end{array}$ & 7 & 0.752 \\
\hline $\begin{array}{l}\text { Extrinsic } \\
\text { Expectancy }\end{array}$ & 7 & 0.781 \\
\hline Empowerment & 5 & 0.832 \\
\hline Goal Clarity & 4 & 0.761 \\
\hline $\begin{array}{l}\text { Overall } \\
\text { Reliability }\end{array}$ & 23 & 0.816 \\
\hline
\end{tabular}

Table 2 depicts the results for Cronbach's Alpha of the scale employed in this research. Cronbach's Alpha of each individual variable in current research ranges between (0.752-0.832) which is a very good and acceptable range. The overall reliability was found to be 0.816 . Specifically, Cronbach Alpha value used to represent the internal reliability view, the view where the items within each of the construct reviewed to validate.

\subsection{Employment Level-wise Analysis and Comparison}

Table 3 shows the regression results of total response generated from survey conducted in different public sector organizations around Hefei City. It depicts the outcome for overall employees on one hand, and on the other hand it depicts the outcome for top and middle level employees. These regression results are very important and noteworthy. In the the outcome of overall model, 94.5\% variability is detected in dependent variable (Public Service Motivation-PSM). 'Empowerment' (0.291), 'Goal Clarity' (0.236) 'Extrinsic Expectancy' (0.301) have a high influence on PSM, whereas 'Intrinsic Motivation' (0.112) have comparatively low impact on Public Service Motivation (PSM). Intrinsic Expectancy which includes constructs like employability for mobility, work importance, and sense of work achievements has a low impact on PSM, because majority of the employees in Public sector organizations are focused on traditional government sector careers. The employees in public sector organizations don't believe on employability for mobility, lateral mobility, and psychological success. They give preference to pay, job, security and promotion. That's why extrinsic expectancy (job. Pay, Security and Promotion) have a high impact on Public Service Motivation (PSM). 
Table 3. Regression results comparing overall, Top, and Middle level employees

\begin{tabular}{|l|l|l|l|}
\hline & Model overall & $\begin{array}{l}\text { Model top } \\
\text { level }\end{array}$ & $\begin{array}{l}\text { Model middle } \\
\text { level }\end{array}$ \\
\hline PSM & & & \\
\hline $\begin{array}{l}\text { Intrinsic } \\
\text { expectancy }\end{array}$ & ${ }^{* *} 0.112$ & ${ }^{* *} 0.143$ & ${ }^{* *} 0.083$ \\
\hline $\begin{array}{l}\text { Extrinsic } \\
\text { expectancy }\end{array}$ & ${ }^{*} 0.301$ & ${ }^{*} 0.332$ & ${ }^{*} 0.267$ \\
\hline Empowerment & ${ }^{*} 0.291$ & ${ }^{*} 0.301$ & ${ }^{*} 0.269$ \\
\hline Goal Clarity & ${ }^{*} 0.236$ & ${ }^{*} 0.276$ & ${ }^{*} 0.281$ \\
\hline $\mathrm{R}^{2}$ & 0.946 & 0.957 & 0.929 \\
\hline Adjusted $\mathrm{R}^{2}$ & 0.945 & 0.950 & 0.924 \\
\hline $\mathrm{F}$ & 888.618 & 134.949 & 217.740 \\
\hline${ }^{* *} \mathrm{p}<0.10,{ }^{*} \mathrm{P}<0.05$ & $\mathrm{~N}=210$ & $\mathrm{~N}=29$ & $\mathrm{~N}=73$ \\
\hline
\end{tabular}

95\% variability is explained in dependent variable PSM in the model of top level employees. 'Empowerment' (0.301), 'Extrinsic Expectancy (0.332), and 'Goal Clarity' (0.276) have a low impact on Public Service Motivation whereas 'Intrinsic Expectancy' (0.143) has comparatively low impact on Public Service Motivation (PSM). The regression results for Top Level employees are consistent with the results for overall employees. Top level employees' shows the magnitude of public service motivation where the variability in PSM of Top level employees is also based upon extrinsic motivational factors such as pay, job safety, advancement and goal simplicity rather based upon employability for flexibility, Job importance, and sense of work achievements. There are many explanations for this but the most obvious one is when employees in organizations reached to a high position they expect minimum chances of promotion (Slow Growth), the strive for more empowerment, want stability in Job, and are more focused on goal clarity. If organizations provide all of these things this will leads towards high Public Service Motivation (PSM) among Top Level Employees. The comparatively low impact factor of 'Intrinsic Expectancy' of (0.143) doesn't mean that top level employees doesn't pay attention to intrinsic motivational factors such as sense of work achievements, work importance, and other intrinsic motivational factors but the intrinsic expectancy among top level employees is not directly \& strongly linked with Public Service Motivation (PSM).

Likewise, the result for model Middle Level as, $93 \%$ variability in the dependent variable (Public Service Motivation-PSM) has been explained. 'Empowerment' (0.269), 'Extrinsic Expectancy' (0.267), and 'Goal Clarity' (0.281) have a significant relationship with Public Service Motivation (PSM). While as usual the results are consistent with 'Intrinsic Expectancy' in Overall and Top Level is (0.083) in Middle level employees, and a low impact creator in PSM. Just like the regression outcome for Overall and Top Level employees suggests that the employees in public sector organizations prefer Extrinsic motivational factors rather than intrinsic motivational, the results for middle level employees suggests the same. For middle level employees in public sector organizations Extrinsic Motivational factors are more important than intrinsic motivational factors. The reason for this might be the deep down embedded culture and environment of governmental organizations. Most Middle Level employees in the start of mid of their careers are more focused on 'Goal Clarity' (0.281) rather than empowerment, pay, and promotion. If middle level employees are clear 
about their goals, they will have a clear sense of their careers/job formation and management, and will be highly committed to deliver effective public service motivation.

Table 4 .Correlation among variables

\begin{tabular}{|llllll|}
\hline$* * \mathrm{P}<0.01$ & $\begin{array}{l}\text { Intrinsic } \\
\text { expectancy } \\
\text { Intrinsic expectancy }\end{array}$ & $\begin{array}{l}\text { Extrinsic } \\
\text { expectancy }\end{array}$ & Empowerment & $\begin{array}{l}\text { Goal } \\
\text { Clarity }\end{array}$ & PSM \\
Extrinsic expectancy & ${ }^{* *} 0.432$ & 1 & & & \\
Empowerment & $* * 0.458$ & $* * 0.521$ & 1 & & \\
Goal Clarity & $* * 0.329$ & ${ }^{* *} 0.415$ & ${ }^{* *} 0.558$ & 1 & \\
PSM & $* * 0.709$ & $* * 0.754$ & $* * 0.831$ & $* * 0.776$ & 1 \\
\hline
\end{tabular}

In Table 4 we can see that all independent variables (IV) 'Intrinsic Expectancy', 'Extrinsic Expectancy', 'Empowerment', and 'Goal Clarity' have significant and positive relationship with dependent variable (DV) Public Service Motivation (PSM). All the significant correlation in the above table has been flagged. This correlation is validating the hypothesis of this study.

\section{Conclusion and Limitations}

The outcomes of this empirical study shows that in public/governmental institutions public service motivation of employees is more dependent upon Extrinsic Motivational factors rather than intrinsic motivational factors. In order to get the most optimum results and performances from their employees' public sector organizations should identify and highlight their intrinsic and extrinsic motivational factors, to achieve employees' satisfaction level for delivering effective public service motivation. As an old saying goes, you have to give something in order to get something, so organizations simply cannot achieve and deliver effective public service motivation without giving rewards and fulfilling the employees need and wants, and entrusting powers and authority. The findings of this research supporting this fact as the intensity of goal clarity (0.236) and the intensity of empowerment (0.291) clearly and significantly affect public service motivation. Empowerment and goal clarity also have a strong effect on public service motivation. In the case of Top and Middle level employees. Surprisingly intrinsic motivational factors have no significant effect on public service motivation in case of overall, middle, and top level employees. The rational of findings in this study depend upon the willingness of the policy makers of public sector organizations and will help them to decide what to give (intrinsic motivation, extrinsic motivation, goal clarity, empowerment) in order to take something (enhancing efficiency through delivering effective 'Public Service Motivations'.

The future studies can involve the following changes and developments: (1) The involvement of top tier employees to understand their perspective. (2) The qualitative approach is massively observed in the existing pool of literature; the adoption of qualitative approach can include the enriched findings for the current study. (3) Inter-provincial level study can conclude much valuable findings in the future studies. (4) The interdisciplinary view can help 
to find the more holistic view to the 'Public Service Motivations' in the case of the current study.

\section{References}

Balfour, D. L., \& Wechsler, B. (1990). Organizational commitment: A reconceptualization and empirical test of public-private differences. Review of Public Personnel Administration, $10(3), 23-40$.

Bellè, N., Bocconi, U., \& Bocconi, S. D. a. (2010). Public Service Motivation: The State of the Art. Reforming the Public Sector: How to Make the Difference?, (June), 1-29.

Blumberg, M., \& Pringle, C. D. (1982). The Missing Opportunity in Organizational Research: Some Implications for a Theory of Work Performance. Academy of Management Review, 7(4), 560-569. https://doi.org/10.5465/AMR.1982.4285240

Brewer, G. A., \& Selden, S. C. (2000). Why Elephants Gallop: Assessing and Predicting Organizational Performance in Federal Agencies. Journal of Public Administration Research and Theory, 10(4), 685-712. https://doi.org/10.1093/oxfordjournals.jpart.a024287

Bright, L. (2008). Does Public Service Motivation Really Make a Difference on the Job Satisfaction and Turnover Intentions of Public Employees? The American Review of Public Administration, 38(2), 149-166. https://doi.org/10.1177/0275074008317248

Buchanan, D., Claydon, T., \& Doyle, M. (1999). Organisation development and change: the legacy of the nineties. Human Resource Management Journal, 9(2), 20-37.

https://doi.org/10.1111/j.1748-8583.1999.tb00194.x

Charbonneau, E., \& Van Ryzin, G. G. (2017). Exploring the Deep Antecedent of Public Service Motivation. International Journal of Public Administration, 40(5), 401-407. https://doi.org/10.1080/01900692.2015.1126731

Conger, J. A., \& Kanungo, R. N. (1988). The Empowerment Process: Integrating Theory and Practice. Academy of Management Review, 13(3), 471-482.

https://doi.org/10.5465/AMR.1988.4306983

Drucker, P. F. (1985). Innovation and entrepreneurship practices and principles. AMACON.

Ghobadian, A., Gallear, D., Viney, H., \& Oregan, N. (2007). Public sector performance improvement through private sector management practices: a satisfactory solution? International Journal of Business Performance Management, 9(4), 363-379.

https://doi.org/10.1504/IJBPM.2007.013360

Gliem, J. A., \& Gliem, R. R. (2003). Calculating, interpreting, and reporting Cronbach's alpha reliability coefficient for Likert-type scales. Midwest Research-to-Practice Conference in Adult, Continuing, and Community Education.

Grindle, M. S. (1997). Divergent Cultures? When Public Organizations Perform Well in Developing Countries. World Development, 25(4), 481-495.

https://doi.org/10.1016/S0305-750X(96)00123-4 


\section{I Macrothink}

Business and Economic Research ISSN 2162-4860 2018, Vol. 8, No. 1

Hart, P. T. (1998). Preventing Groupthink Revisited: Evaluating and Reforming Groups in Government. Organizational Behavior and Human Decision Processes, 73, 306-326.

https://doi.org/10.1006/obhd.1998.2764

Kingsley, G. A., \& Reed, P. N. (1991). Decision process models and organizational context: Level and sector make a difference. Public Productivity \& Management Review, 397-413.

Naff, K. C., \& Crum, J. (1999). Working for America: Does Public Service Motivation Make a Difference? Review of Public Personnel Administration, 19(4), 5-16.

https://doi.org/10.1177/0734371X9901900402

Panagiotis, M., Alexandros, S., \& George, P. (2014). Organizational Culture and Motivation in the Public Sector. The Case of the City of Zografou. Procedia Economics and Finance, 14(14), 415-424. https://doi.org/10.1016/S2212-5671(14)00730-8

Pandey, S. K., Wright, B. E., \& Moynihan, D. P. (2008). Public Service Motivation and Interpersonal Citizenship Behavior in Public Organizations: Testing a Preliminary Model. International Public Management Journal, 11(1), 89-108.

https://doi.org/10.1080/10967490801887947

Perry, J. L., \& Hondeghem, A. (2008). Building Theory and Empirical Evidence about Public Service Motivation. International Public Management Journal, 11(1), 3-12.

https://doi.org/10.1080/10967490801887673

Perry, J. L., \& Wise, L. R. (1990). The Motivational Bases of Public Service. Public Administration Review, 50(3), 367. https://doi.org/10.2307/976618

Rainey, H. G. (1982). Reward Preferences among Public and Private Managers: In Search of the Service Ethic. The American Review of Public Administration, 16(4), 288-302.

https://doi.org/10.1177/027507408201600402

Rainey, H. G., \& Steinbauer, P. (1999). GALLOPING ELEPHANTS: DEVELOPING ELEMENTS OF A THEORY OF EFFECTIVE GOVERNMENT ORGANIZATIONS. Journal of Public Administration Research and Theory, 9(1), 1-32.

https://doi.org/10.1093/oxfordjournals.jpart.a024401

Robbins, S. P. (2009). Organizational Behavior, 13/E. Pearson Education India.

Scully, J. P. (1993). How to really change the federal government. Global Business and Organizational Excellence, 13(1), 29-38.

Ugboro, I., \& Obeng, K. (2001). Managing the Aftermaths of Contracting in Public Transit Organizations: Employee Perception Of, Job Security, Organizational Commitment and Trust. Transportation Institute, North Carolina Agricultural and Technical State University, School of Business \& Economics.

Vandenabeele, W., \& Ban, C. (2009). The impact of public service motivation in an international organization: job satisfaction and organizational commitment in the European Commission. Paper. International Review of Administrative Sciences. 


\section{Macrothink}

Business and Economic Research

ISSN 2162-4860

2018, Vol. 8, No. 1

Verbeeten, F. H. M. (2008). Performance management practices in public sector organizations: Impact on performance. Accounting, Auditing \& Accountability Journal, 21(3), 427-454. https://doi.org/10.1108/09513570810863996

Wilson, P. A. (1999). A theory of power and politics and their effects on organizational commitment of senior executive service members. Administration \& Society, 31(1), 120-141.

Wright, B. E., Hassan, S., \& Christensen, R. K. (2017). Job Choice and Performance: Revisiting Core Assumptions about Public Service Motivation. International Public Management Journal, 20(1), 108-131. https://doi.org/10.1080/10967494.2015.1088493

Yousef, D. A. (1998). Satisfaction with job security as a predictor of organizational commitment and job performance in a multicultural environment. International Journal of Manpower, 19(3), 184-194. https://doi.org/10.1108/01437729810216694

Zeffane, R. (1996). Dynamics of strategic change: critical issues in fostering positive organizational change. Leadership \& Organization Development Journal, 17(7), 36-43. https://doi.org/10.1108/01437739610148376

\section{Copyright Disclaimer}

Copyright for this article is retained by the author(s), with first publication rights granted to the journal.

This is an open-access article distributed under the terms and conditions of the Creative Commons Attribution license (http://creativecommons.org/licenses/by/3.0/). 